\title{
TIBE STOCK MARKET CONTAGION IN THE EARLY STAGES OF THE GLOBAL FINANCIAL CRISIS: THE EXPERIENCE OF THE GCC COUNTRIES
}

\author{
Imad Moosa \\ Monash University, Australia and Kuwait \\ University
}

\begin{abstract}
This study examined stock market contagion from the United States to the markets of the GCC countries during the period 2007-08. These countries (Bahrain, Kuwait, Oman, Qatar, Saudi Arabia and the United Arab Emirates) were also experiencing accelerating debt levels, overheated real estate markets, and drying up of liquidity. The main hypothesis under investigation is that the collapse of the GCC stock markets did not result purely from contagion, in the sense that these markets did not follow closely the US market during that period. It is argued that local factors were more influential in triggering the collapse and that those markets would have collapsed with or without the global financial crisis. The empirical results show rather limited evidence for the effect of U.S. stock prices on GCC stock prices and a much more important role for oil prices. However, neither of these variables alone can explain the behaviour of GCC stock prices during the period under investigation because of the role played by the domestic factors that caused bubbles and crashes.
\end{abstract}

Keywords: Contagion, GCC markets, Oil Prices and Stock Prices, Market Bubble JEL Classifications: G15, G11, F30.

\section{Introduction}

The global financial crisis has resulted from the U.S. subprime crisis, which arose from excessive growth of subprime lending as financial institutions offered nonstandard mortgages to individuals with dubious credit profiles. The crisis has been described as a "credit crunch" and a "credit squeeze", two terms that differ only to the extent of the curtailment in credit supply. Whether it is a "crunch" or a "squeeze", the present crisis is characterised by a decline in the terms and availability of credit for consumers and businesses, which has adversely affected 
consumption and investment spending, thus putting the economies of the U.S. and other countries in recession. Another characteristic of the crisis is disorder in financial markets, as financial institutions find it difficult to determine the true (or fair) value of assets that are no longer traded in sufficient volumes. This crisis is far more complex than earlier crises because financial innovation has (through securitisation) allowed the creation of complex assets whose risk profiles are difficult to assess and which are not easy to price. Another characteristic of the crisis is the speed with which it spread from the US to other countries, through a contagious effect that was transmitted via several channels.

The financial markets and economies of emerging countries have been adversely affected by the crisis. The objective of this paper is to examine and evaluate the effects of the crisis on the six oil-exporting countries of the Gulf Cooperation Council (GCC): Bahrain, Kuwait, Oman, Qatar, Saudi Arabia and the United Arab Emirates. Specifically, this paper deals with stock market contagion during the early stages of the crisis (2007-2008). For the purpose of empirical analysis, contagion is proxied by the effect of changes in US stock prices on stock prices in these countries.

The empirical work was based on a sample of daily data, covering the period January 2007 to December 2008, on stock prices in seven stock markets, including two UAE markets: Abu Dhabi and Dubai. The reason for choosing two markets from the same country is that they are located in two different states (emirates) with different oil endowments and different development policies (more explosive in Dubai than in Abu Dhabi). Since we are also going to examine the effect of oil prices, a sample of daily oil prices covering the same

- period has been collected. Data on the GCC markets were obtained from the Gulf Investment Corporation, whereas the Dow Jones data were obtained from the Yahoo Finance website. Data on oil prices were obtained from Bloomberg.

\section{Effect of the Crisis on Financial Institutions and Markets in GCC Countries}

Before we examine the effect of the crisis on the stock markets of the GCC countries, it may be useful to consider its effect on financial institutions and other financial markets in these countries. As is the case anywhere else in the world, financial institutions in the GCC countries have been affected by the crisis via several channels: (i) direct exposure to the US housing market, real estate products or CDOs; (ii) exposure to institutions (both as shareholders and creditors) that have direct exposure as in (i); and (iii) the effect of the crisis on the liquidity needs of the GCC financial institutions.

We start with the direct and indirect exposure to subprime losses. By the end of 2008, the GCC countries held foreign assets valued at $\$ 1.8$ to 2 trillion, about $60 \%$ of which were dollar denominated. Only a limited number of GCC banks have publicly admitted exposure to subprime losses, with estimated losses amounting to $\$ 3$ billion, although some estimates put the figure at $\$ 10$ billion 
(Hussain, 2008). It is, however, believed that most of the losses resulting from direct and indirect exposure to the subprime market have been incurred by sovereign wealth funds such as the Abu Dhabi Investment Authority (ADIA) and the Kuwait Investment Authority (KIA). According to Woertz (2008), these funds represent sophisticated investors with a considerable equity component, which means that their exposure to the current market turmoil must be considerable. They probably invested in risky assets, such as CDOs, more than banks. The KIA injected massive amounts into Merrill Lynch, a US investment bank that has experienced a substantial loss of value as a result of direct exposure to "toxic assets". The unavailability of exact and detailed figures prevents us from saying anything definitive about the direct and indirect losses incurred by the GCC financial institutions.

As far as liquidity needs are concerned, Woertz (2008) argued that "while the direct subprime exposure of GCC banks has been limited thus far, the real problem for the GCC banks lies in the direct exposure to increased costs of funding amidst maturity mismatches and credit exposure to local consumers, project and real estate financing". What makes things worse is that even before the onset of the crisis, there was already a liquidity squeeze resulting from negative real interest rates. Foreign funds used for speculating on what was thought to be an imminent revaluation of local currencies against the US dollar were withdrawn as speculators realised that it would not take place. Foreign investors also pulled out because of the need for short-term capital to rebalance their portfolios and cover losses, leading to the removal of liquidity from the banking system, particularly from the subsidiaries of foreign banks.

As a result of the crisis, financial institutions in the GCC faced (and still do) constrained financing conditions while enduring losses resulting from exposure to the local stock and real estate markets, both of which had experienced bursting bubbles. It seems, therefore, that the status quo has not resulted entirely from, but it has been exacerbated by, the global financial crisis. According to the Business Monitor International (2008), the current liquidity crunch in GCC countries is not particularly linked to the global financial crisis, and it is the result of strong demand by a rapidly growing private sector.

The crisis has also affected GCC financial markets other than stock markets. The crisis has to a certain extent disrupted the syndicated loan markets. In the second half of 2008, interbank rates across the GCC soared. In the UAE, the usually liquid one-year market has almost dried up and the three month rates rose 230 basis points in three months. The rise materialised despite cuts in policy rates and the fall in LIBOR, which LIBOR has historically followed. The other liquid regional interbank markets saw similar trends, with Gulf spreads on LIBOR moving far above the medium-term norm. Also, spreads (over LIBOR) for corporate bonds in the GCC rose from around 145 at the end of 2007 to 500 basis points at the end of 2008. GCC countries were affected through exposure to foreign financial markets that have brought in large private capital flows to the region during the recent boom years. 


\section{A. Stylised Facts on the Effect of the Crisis on GCC Stock Markets}

Figure 1 displays daily stock prices over the period 2 January 2007-31 December 2008 (or close to the year end) along with the Dow Jones (numbers on the horizontal axis refer to daily observations). A careful examination of the data reveals that the GCC stock markets have endured losses not only because of the global financial crisis but also because these markets were in a bubble before the recognition of the crisis, a bubble that was created by purely domestic factors, as the previous discussion indicates. The locations of turning

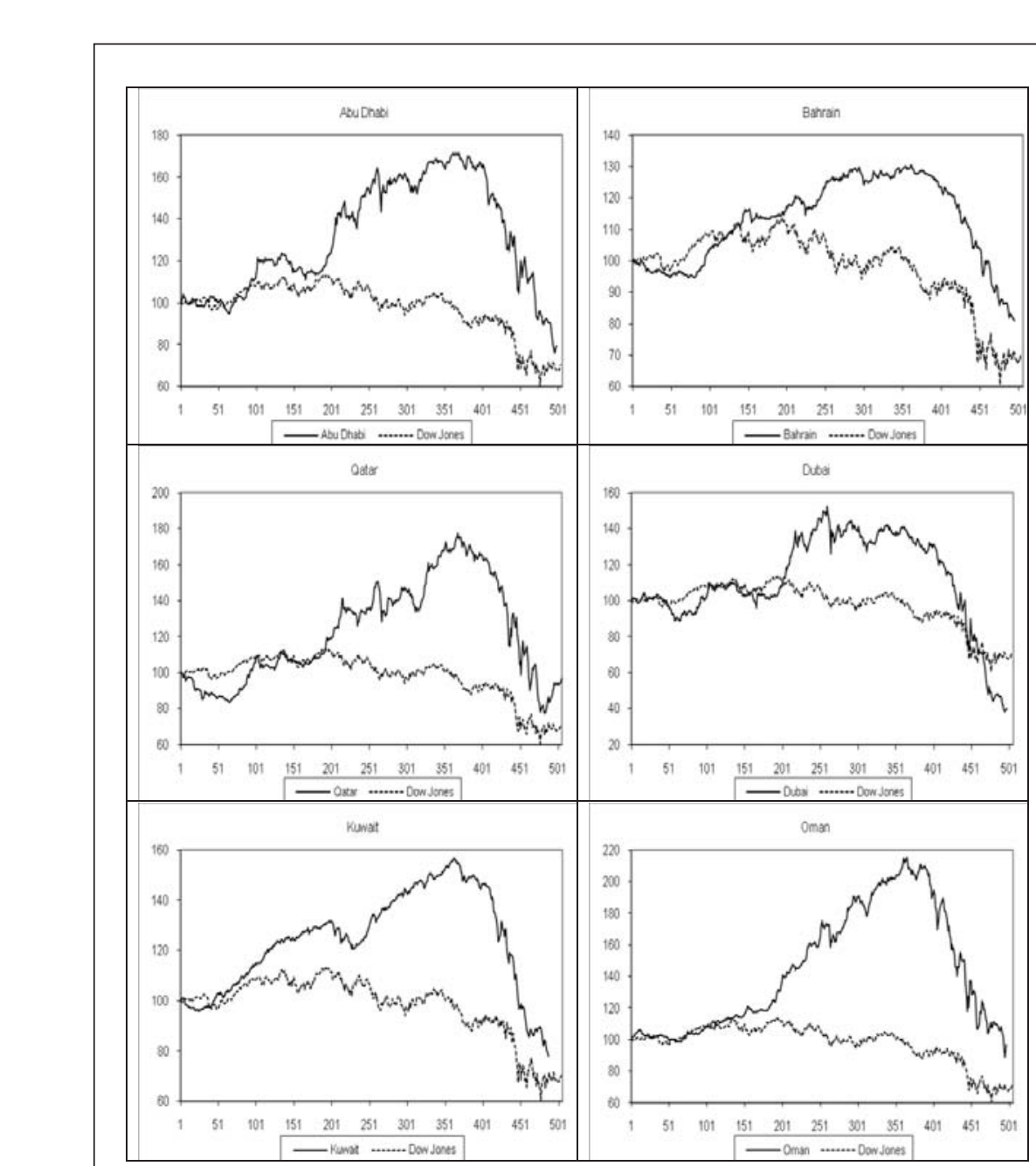

Figure 1. Stock Prices Relative to the Dow Jones (2/01/07=100) 


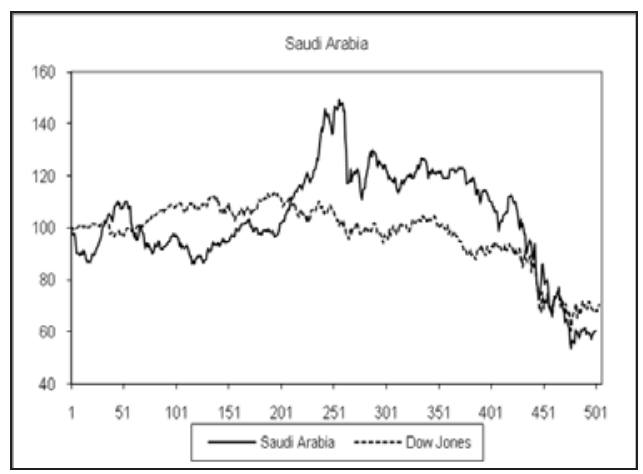

Figure 1. Stock Prices Relative to the Dow Jones $(2 / 01 / 07=100)$

points in GCC stock prices relative to the Dow Jones indicate decoupling of the GCC markets from the US market. Consider the figures in Table 1, which reports changes in stock prices in the seven GCC markets normalised on the value of 100 on 2 January 2007. The column "last observation" refers to the price at the end of the sample period. The peak value refers to the highest value of the price and when that value occurred (month/year). We can see that most markets peaked in June 2008, whereas the Dow reached its peak value in October 2007. Thus, even as the US stock market was declining because of the crisis, the GCC stock markets kept on rising.

\section{Table 1}

Stock Price Changes (02/01/07-31/12/08)

\begin{tabular}{lccccc}
\hline Market & $\begin{array}{c}\text { First } \\
\text { Observation }\end{array}$ & $\begin{array}{c}\text { Last } \\
\text { Observation }\end{array}$ & $\begin{array}{c}\text { Peak Value } \\
(\mathrm{mm} / \mathrm{yy})\end{array}$ & $\begin{array}{c}\text { First to } \\
\text { Peak }(\%)\end{array}$ & $\begin{array}{c}\text { Peak to } \\
\text { Last }(\%)\end{array}$ \\
\hline Abu Dhabi & 100 & 79.75 & $171.81(06 / 08)$ & 71.81 & -53.58 \\
Bahrain & 100 & 81.04 & $130.39(06 / 08)$ & 30.39 & -37.84 \\
Dubai & 100 & 39.66 & $152.52(01 / 08)$ & 52.52 & -73.99 \\
Kuwait & 100 & 77.84 & $156.58(06 / 08)$ & 56.38 & -50.28 \\
Oman & 100 & 96.72 & $215.25(06 / 08)$ & 115.52 & -55.06 \\
Qatar & 100 & 91.23 & $177.33(06 / 08)$ & 77.33 & -45.46 \\
Saudi Arabia & 100 & 60.26 & $149.26(01 / 08)$ & 49.26 & -59.62 \\
(U.S.) Dow Jones & 100 & 70.54 & $113.54(10 / 07)$ & 13.54 & -38.04 \\
\hline
\end{tabular}

The column "first to peak" refers to the percentage change in stock prices between the first observation and the peak. Stock markets of the GCC countries rose much faster than the U.S. market, which registered a rise of $13.54 \%$, compared with the Omani market that rose by $115.52 \%$. The last column "peak to last" shows the percentage change in stock prices between the peak and the 
last observation. Apart from Bahrain, GCC markets lost more of their values than the U.S. market as represented by the Dow. These figures provide prima facie evidence for the proposition that the GCC markets experienced their own bubbles and crashes, which were more vibrant (in the case of bubbles) and more severe (in the case of crashes) than the corresponding bubbles and crashes exhibited by the Dow.

Table 2 reports correlations of the GCC markets with the U.S. market. Correlations are not particularly high and they differ significantly from one market to another, ranging between zero in the case of Oman and 0.52 for Saudi Arabia and Dubai. Volatility, as measured by the standard deviation of the daily percentage changes in stock prices, also shows significant variation, with some markets being almost three times as volatile as the U.S. market. Again, these - figures indicate that domestic factors that had no relation to the global financial crisis propelled the GCC markets, causing the bubble and crash behaviour that we have seen.

Table 2

Stock Price Correlation and Volatility

\begin{tabular}{lcc}
\hline Market & Correlation with U.S. & Standard Deviation of Daily Percentage Changes \\
\hline Abu Dhabi & 0.18 & 1.52 \\
Bahrain & 0.34 & 0.71 \\
Dubai & 0.55 & 2.10 \\
Kuwait & 0.34 & 0.90 \\
Oman & 0.00 & 4.80 \\
Qatar & 0.09 & 1.89 \\
Saudi Arabia & 0.52 & 4.96 \\
(U.S.) Dow Jones & 1.00 & 1.81 \\
\hline
\end{tabular}

\section{The Effect of Contagion}

\section{A. Methodology and Empirical Results}

The methodology used to test the contagion hypothesis in this paper was based on the structural time series model of Harvey $(1989,1997)$, which is used to represent an observed time series in terms of its unobserved components. This model may be written as:

$$
p_{t}=\mu_{t}+\phi_{t}+\varepsilon_{t}
$$

where $p_{T}$ is the logarithm of stock prices, $\mu_{\mathrm{t}}$ is the trend component, $\phi_{t}$ is the cyclical component, and $\varepsilon_{t}$ is the random component, which is assumed to be white noise. The trend component, which represents the long-term movement 
in a series, is assumed to be stochastic and linear. This component can be represented by:

$$
\begin{aligned}
& \mu_{t}=\mu_{t-1}+\beta_{t-1}+\eta_{t} \\
& \beta_{t}=\beta_{t-1}+\zeta_{t}
\end{aligned}
$$

where $\eta_{t} \sim \operatorname{NID}\left(0, \sigma_{\eta}^{2}\right)$, and $\zeta_{t} \sim \operatorname{NID}\left(0, \sigma_{\zeta}^{2}\right) . \mu_{\mathrm{t}}$ is a random walk with a drift factor, $\beta_{\mathrm{t}}$, which follows a first order autoregressive process as represented by equation (3). This is a general representation of the trend, which encompasses all other possibilities. For example, this process collapses to a simple random walk with drift if $\sigma_{\zeta}^{2}=0$, and to a deterministic linear trend if $\sigma_{\eta}^{2}=0$ as well. If, on the other hand, $\sigma_{\eta}^{2}=0$ while $\sigma_{\zeta}^{2} \neq 0$ then the process will have a trend which changes relatively smoothly. ${ }^{1}$

The cyclical component, which is assumed to be a stationary linear process, may be represented by:

$$
\phi_{t}=a \cos \theta t+b \sin \theta t
$$

where $t$ is time and the amplitude of the cycle is given by $\left(a^{2}+b^{2}\right)^{\frac{1}{2}}$. In order to make the cycle stochastic, the parameters $a$ and $b$ are allowed to evolve over time, while preserving continuity is achieved by writing down a recursion for constructing $\phi$ before introducing the stochastic components. If disturbances and a damping factor are also introduced, we obtain:

$$
\left[\begin{array}{l}
\phi_{t} \\
\phi_{t}^{*}
\end{array}\right]=\rho\left[\begin{array}{cc}
\cos \theta & \sin \theta \\
-\sin \theta & \cos \theta
\end{array}\right]\left[\begin{array}{c}
\phi_{t-1} \\
\phi_{t-1}^{*}
\end{array}\right]+\left[\begin{array}{c}
\omega_{t} \\
\omega_{t}^{*}
\end{array}\right]
$$

such that and $\phi_{0}=a$ and $\phi_{0}^{*}=b \cdot \omega_{\mathrm{t}}$ are $\omega_{t}^{*}$ uncorrelated white noise disturbances with variances $\sigma_{\omega}^{2}$ and $\sigma_{\omega^{*}}^{2}$, respectively. The parameters $0 \leq \theta \leq \pi$ and $0 \leq \rho \leq 1$ are the frequency of the cycle and the damping factor on the amplitude, respectively.

Once it has been written in this form, the model can be estimated by maximum likelihood, using the Kalman filter to update the state vector (whose elements are the time series components), as new observations become available. Related smoothing algorithms can be used to obtain the best estimate of the state vector at any point in time within the sample period. ${ }^{2}$

\footnotetext{
${ }^{1}$ Harvey (1989, pp. 510-511) lists all of the possibilities. Koopman, Harvey, Doornik and Shephard (1995) identify several models including: a constant term model, local level model, random walk with and without drift, local level with fixed slope, a smooth trend model, etc.

${ }^{2}$ For details of the estimation method, see Harvey (1989, chapters 4 and 7) and Koopman et al. (1995, chapter 14). For applications of this technique in economics and finance, see Moosa (2006) and Moosa and Gazos (2009).
} 
To test the contagion hypothesis, the basic structural time series model represented by equation (1) must be modified by introducing an explicit explanatory variable. Thus, the modified model is:

$$
p_{i, t}=\mu_{i, t}+\phi_{i, t}+\delta p_{U S, t}+\varepsilon_{i, t}
$$

where $\mathrm{P}_{i}$, is the logarithm of the stock price index in market $i$, such that $i=$ $1,2, \ldots, 7$ and $P_{u s, t}$ is the logarithm of US stock prices measured by the Dow Jones index. ${ }^{3}$ The hypothesis of contagion is confirmed if the coefficient on $P_{u s, t}$ is positive and statistically significant.

The beauty of this model is that it allows us to examine the effect of factors other than US stock prices even without identifying them explicitly. The "effect of these factors is reflected in the behaviour of the components $\mu$ and $\phi$. If these components are statistically significant while $\delta$ is also significant, then this means that factors other than US stock prices affect stock prices in the GCC countries. If, on the other hand, the components are insignificant while $\delta$ is significantly positive, this means that the only factor affecting stock prices in the GCC countries is US stock prices, thus providing very strong evidence for the contagion hypothesis. If, however, $\delta$ turns out to be insignificant while the components are significant, this means that only other factors affect stock prices in the GCC countries, which provides evidence against the contagion hypothesis.

Table 3 reports the results of estimating equation (6) over the whole sample period. The results include the final state vector (with the $t$ statistics given - in parentheses), the coefficient of determination $\left(\mathrm{R}^{2}\right)$, the modified coefficient of determination $\left(R_{d}^{2}\right)$ and three diagnostic test statistics: the Durbin Watson (DW) statistic, the Ljung-Box (1978) test statistic for serial correlation $(Q)$, and a test statistic for heteroscedasticity $(H){ }^{4}$ We can see that the model is reasonably well-determined in terms of goodness of fit and the diagnostic tests (all equations have positive $R_{d}^{2}$ ). In all cases the level of the trend (which is equivalent to the constant term in a conventional regression) is highly significant, whereas the slope (which is equivalent to the coefficient on a deterministic time trend in a conventional regression) is significantly negative in five cases.

${ }^{3}$ No seasonal component is included in equation (6) because daily data are used in this study.

${ }^{4}$ The modified coefficient of determination, $\left(R_{d}^{2}\right)$ is calculated on the basis of the first differences rather than the levels of the variables, and it is more appropriate for trended data. A model with a positive $R_{d}^{2}$ is better than a random walk with a drift model $\left(R_{d}^{2}\right.$ can be negative). The $Q$ statistic is calculated as $Q(n, k))$ where $n$ is the number of autocorrelation coefficients and $k$ is the number of estimated parameters. It has a $\chi^{2}(k)$ distribution. The test statistic for heteroscedasticity, $H(h)$, is calculated as the ratio of the squares of the last $h$ residuals to the squares of the first $h$ residuals, where $h$ is the closest integer to one third of the sample size. It is distributed as $F(h, h)$. 
Table 3

Estimation Results of Equation (6): Whole Period*

\begin{tabular}{cccccccc}
\hline & $\begin{array}{c}\text { Abu } \\
\text { Dhabi }\end{array}$ & Bahrain & Dubai & Kuwait & Oman & Qatar & $\begin{array}{c}\text { Saudi } \\
\text { Arabia }\end{array}$ \\
\hline$\mu$ & 4.682 & 4.362 & 3.102 & 4.439 & 3.778 & 4.275 & 3.226 \\
& $(31.19)$ & $(62.71)$ & $(14.91)$ & $(51.38)$ & $(22.61)$ & $(22.08)$ & $(14.83)$ \\
$\beta$ & -0.008 & -0.004 & -0.012 & -0.008 & -0.006 & -0.002 & -0.004 \\
& $-3.31)$ & $(-3.83)$ & $(-3.86)$ & $(-3.84)$ & $(-2.53)$ & $(-0.69)$ & $(-1.64)$ \\
$\phi$ & 0.006 & -0.005 & 0.008 & -0.008 & 0.015 & -0.008 & 0.005 \\
& $(1.45)$ & $(-2.79)$ & $(1.74)$ & $(-3.78)$ & $(3.29)$ & $(-1.78)$ & $(1.69)$ \\
$\phi^{*}$ & -0.004 & -0.005 & -0.011 & 0.003 & 0.012 & -0.003 & -0.007 \\
& $-0.92)$ & $(-2.93)$ & $(-2.34)$ & $(1.49)$ & $(2.60)$ & $(-0.68)$ & $(-2.15)$ \\
$\delta$ & -0.074 & 0.009 & 0.134 & -0.018 & 0.183 & 0.065 & 0.206 \\
& $-1.07)$ & $(0.54)$ & $(2.74)$ & $(-0.89)$ & $(4.66)$ & $(1.43)$ & $(3.98)$ \\
$\mathrm{R}^{2}$ & 0.90 & 0.95 & 0.92 & 0.99 & 0.96 & 0.86 & 0.88 \\
$R_{d}^{2}$ & 0.07 & 0.10 & 0.08 & 0.15 & 0.11 & 0.03 & 0.05 \\
$D W$ & 1.83 & 1.85 & 1.99 & 1.87 & 1.78 & 1.87 & 1.94 \\
$Q$ & 26.03 & 27.63 & 20.95 & 21.85 & 26.87 & 23.98 & 25.73 \\
$H$ & 1.19 & 1.24 & 1.20 & 1.23 & 1.26 & 1.27 & 1.19 \\
\hline
\end{tabular}

$* \mathrm{Q}$ is distributed as $\chi^{2}(18)$, which gives a $5 \%$ critical value of 28.86 . $\mathrm{H}$ is distributed as $\mathrm{F}(165,165)$, which gives a $5 \%$ critical value of 1.29 .

Table 4

Estimation Results of Equation (6): First Sub-sample*

\begin{tabular}{cccccccc}
\hline & $\begin{array}{c}\text { Abu } \\
\text { Dhabi }\end{array}$ & Bahrain & Dubai & Kuwait & Oman & Qatar & $\begin{array}{c}\text { Saudi } \\
\text { Arabia }\end{array}$ \\
\hline$\mu$ & 5.120 & 4.327 & 4.432 & 4.896 & 5.022 & 4.572 & 4.786 \\
& $(14.73)$ & $(20.88)$ & $(9.62)$ & $(26.25)$ & $(20.10)$ & $(12.68)$ & $(8.15)$ \\
$\beta$ & 0.003 & 0.0004 & 0.000 & 0.001 & 0.006 & 0.008 & -0.001 \\
& $(1.33)$ & $(0.37)$ & $(0.17)$ & $(0.87)$ & $(3.01)$ & $(2.32)$ & $(-0.30)$ \\
$\phi$ & 0.002 & 0.000 & -0.0005 & 0.003 & 0.005 & 0.003 & -0.002 \\
& $(1.04)$ & $(0.01)$ & $(-0.26)$ & $(3.66)$ & $(1.70)$ & $(0.75)$ & $(-0.25)$ \\
$\phi^{*}$ & 0.006 & 0.000 & 0.005 & -0.001 & 0.004 & 0.0002 & -0.002 \\
& $(3.45)$ & $(0.001)$ & $(2.50)$ & $(-0.39)$ & $(1.39)$ & $(0.05)$ & $(-0.14)$ \\
$\delta$ & -0.069 & 0.088 & 0.043 & -0.007 & -0.035 & 0.039 & -0.045 \\
& $(-0.94)$ & $(1.02)$ & $(0.44)$ & $(-0.14)$ & $(-0.65)$ & $(0.51)$ & $(-0.35)$ \\
$\mathrm{R}^{2}$ & 0.94 & 0.92 & 0.90 & 0.95 & 0.89 & 0.99 & 0.82 \\
$R_{d}^{2}$ & 0.05 & 0.03 & 0.01 & 0.06 & 0.01 & 0.08 & -0.005 \\
$D W$ & 1.78 & 1.92 & 2.00 & 1.97 & 1.77 & 1.83 & 1.97 \\
$Q$ & 12.70 & 13.58 & 10.27 & 7.21 & 8.80 & 12.99 & 4.59 \\
$H$ & 1.02 & 1.36 & 1.18 & 0.71 & 0.89 & 0.49 & 0.28 \\
\hline
\end{tabular}

* $\mathrm{Q}$ is distributed as $\chi^{2}(18)$, which gives a $5 \%$ critical value of $16.91 . \mathrm{H}$ is distributed as $\mathrm{F}(63,63)$, which gives a $5 \%$ critical value of 1.52 . 
Table 5

Estimation Results of Equation (6): Second Sub-sample*

\begin{tabular}{cccccccc}
\hline & $\begin{array}{c}\text { Abu } \\
\text { Dhabi }\end{array}$ & Bahrain & Dubai & Kuwait & Oman & Qatar & $\begin{array}{c}\text { Saudi } \\
\text { Arabia }\end{array}$ \\
\hline$\mu$ & 4.668 & 4.388 & 3.029 & 4.446 & 3.879 & 4.266 & 3.129 \\
& $(25.23)$ & $(53.78)$ & $(11.32)$ & $(40.84)$ & $(18.45)$ & $(17.52)$ & $(12.02)$ \\
$\beta$ & -0.008 & -0.005 & -0.003 & -0.007 & -0.005 & -0.002 & -0.004 \\
& $(-2.82)$ & $(-3.46)$ & $(-2.13)$ & $(-3.12)$ & $(-2.33)$ & $(-0.72)$ & $(-1.28)$ \\
$\phi$ & 0.007 & -0.005 & 0.007 & -0.008 & 0.026 & -0.007 & 0.005 \\
& $(1.310$ & $(-2.37)$ & $(1.27)$ & $(-3.01)$ & $(-1.32)$ & $(-1.35)$ & $(1.15)$ \\
$\phi^{*}$ & -0.004 & -0.005 & -0.001 & 0.003 & 0.053 & -0.002 & -0.007 \\
& $(-0.69)$ & $(-2.36)$ & $(-1.95)$ & $(1.29)$ & $(1.92)$ & $(-0.47)$ & $(-1.76)$ \\
$\delta$ & -0.070 & 0.003 & 0.152 & -0.019 & 0.170 & 0.068 & .225 \\
& $(-1.61)$ & $(0.14)$ & $(2.41)$ & $(-0.76)$ & $(3.47)$ & $(1.18)$ & $(3.72)$ \\
$\mathrm{R}^{2}$ & 0.93 & 0.97 & 0.88 & 0.99 & 0.98 & 0.84 & 0.90 \\
$R_{d}^{2}$ & 0.08 & 0.12 & 0.05 & 0.14 & 0.13 & 0.03 & 0.07 \\
$D W$ & 1.62 & 1.80 & 1.94 & 1.58 & 1.91 & 1.71 & 1.91 \\
$Q$ & 21.48 & 21.03 & 17.28 & 20.57 & 21.83 & 20.74 & 20.70 \\
$H$ & 1.32 & 1.21 & 1.23 & 1.27 & 1.19 & 1.20 & 1.01 \\
\hline
\end{tabular}

$* \mathrm{Q}$ is distributed as $\mathrm{X}^{2}(18)$, which gives a $5 \%$ critical value of $22.36 . \mathrm{H}$ is distributed as $\mathrm{F}(99,99)$, which gives a $5 \%$ critical value of 1.39 .

The cyclical component is also significant in some cases. The coefficient on the explanatory variable is significantly positive in three cases only. There is, therefore, more evidence for the role played by other factors than for the role played by US stock prices, providing only weak evidence for contagion.

It has been established that stock markets tend to be more strongly correlated when they are falling (particularly when they are falling rapidly). For this reason, equation (6) was estimated by dividing the sample period into two sub-samples, the first extending between the beginning of the sample and observation number 194, which marks the peak of the Dow Jones, whereas the second sub-sample covers the subsequent period. ${ }^{5}$ The results are reported in Tables 4 and 5, for the two sub-samples. Again, the model seems to be well determined in terms of the goodness of fit and diagnostics, but again the results show only limited evidence for contagion. There is no effect of US stock prices on GCC stock prices in the first sub-sample, but a significant effect on these markets in the second sub-sample, when the markets were going up. ${ }^{6}$ For nearly eight months stock prices in GCC countries were rising while the Dow was falling, providing some indication that other factors must have been influencing stock prices in GCC markets.

\footnotetext{
${ }^{5}$ The first sub-sample extends between 2 January 2007 and 4 October 2007. The second sub-sample covers the rest of the period until the end of 2008.

${ }^{6}$ It seems, therefore, that the positive effect of US stock prices on the markets of Dubai, Oman and Saudi Arabia over the whole sample period is a reflection of the effect arising in the second sub-sample, when the Dow was going down. These markets were affected by the decline, but not by the rise, of the Dow, which means that the effect is asymmetric.
} 


\section{B. Evidence on the Effect of Oil Prices}

The question that arises from the examination of the results presented in the previous section is the following: what are the other factors that influence stock prices in GCC countries if US stock prices played a minor role? One variable that is worthy of consideration is bound to be oil prices.

Figure 2 displays stock prices in GCC markets relative to the price of crude oil measured in dollars per barrel. In all cases we see remarkable similarity of the time paths of stock prices and that of the oil price. Figure 2 shows the correlation coefficients of stock prices with the price of oil, as compared to correlation with the Dow Jones. It is obvious that GCC stock prices are much more highly correlated with the price of oil than with the Dow and that the Dow is very weakly correlated with the oil price. For this reason it seems to be worthwhile to examine the effect of the price of oil formally. This can be done by re-writing equation (6) as:

$$
p_{i, t}=\mu_{i, t}+\phi_{i, t}+\lambda z_{t}+\varepsilon_{i, t}
$$

where $Z_{\mathrm{t}}$ is the logarithm of the price of oil.

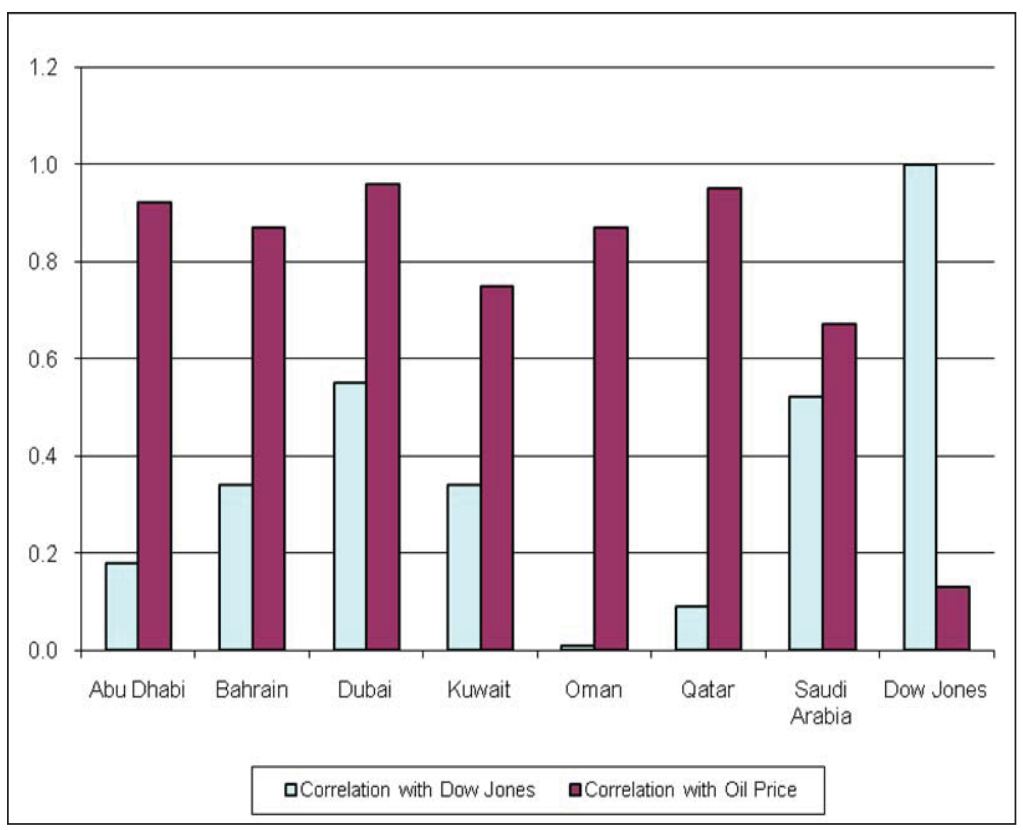

Figure 2. Correlations with the Dow Jones and Oil Price 
Table 6 reports the results of estimating equation (7) in which the explanatory variable is the price of oil. We can see that the coefficient on the explanatory variable is significantly positive in all cases, implying positive effect of the price of oil on stock prices in GCC countries. However, we can still see statistically significant components, particularly the level of the trend. The implication of these results is that while it is evident that the price of oil had a more important effect on stock prices in GCC countries than US stock prices, the effect of other unidentified factors is even more significant.

Table 6

Estimation Results of Equation (7): Whole Period*

\begin{tabular}{cccccccc}
\hline & $\begin{array}{c}\text { Abu } \\
\text { Dhabi }\end{array}$ & Bahrain & Qatar & Dubai & Kuwait & Oman & $\begin{array}{c}\text { Saudi } \\
\text { Arabia }\end{array}$ \\
\hline$\mu$ & 4.159 & 4.434 & 4.557 & 3.691 & 4.279 & 4.512 & 4.30 \\
& $(53.10)$ & $(111.42)$ & $(49.99)$ & $(33.93)$ & $(68.48)$ & $(48.98)$ & $(35.00)$ \\
$\beta$ & -0.007 & -0.005 & -0.003 & -0.013 & -0.008 & -0.006 & -0.007 \\
& $(-3.26)$ & $(-3.87)$ & $(-0.93)$ & $(-3.82)$ & $(-4.01)$ & $(-2.53)$ & $(-2.29)$ \\
$\phi$ & 0.013 & -0.005 & 0.015 & .006 & -0.009 & 0.013 & -0.009 \\
& $(1.08)$ & $(-2.73)$ & $(1.28)$ & $(1.26)$ & $(-4.21)$ & $(2.82)$ & $(-2.91)$ \\
$\phi^{*}$ & 0.032 & -0.005 & -0.006 & -0.011 & 0.003 & 0.009 & -0.002 \\
& $(2.47)$ & $(-2.95)$ & $(-0.54)$ & $(-2.22)$ & $(1.23)$ & $(1.99)$ & $(-0.46)$ \\
$\lambda$ & 0.059 & 0.043 & 0.061 & 0.048 & 0.038 & 0.041 & 0.036 \\
& $(2.73)$ & $(2.32)$ & $(2.65)$ & $(2.61)$ & $(2.26)$ & $(2.38)$ & $(2.21)$ \\
$\mathrm{R}^{2}$ & 0.95 & 0.96 & 0.87 & 0.84 & 0.99 & 0.85 & 0.80 \\
$R_{d}^{2}$ & 0.10 & 0.11 & 0.06 & 0.05 & 0.26 & 0.05 & 0.02 \\
$D W$ & 1.92 & 1.87 & 1.89 & 2.01 & 1.88 & 1.83 & 1.92 \\
$Q$ & 23.29 & 25.64 & 25.93 & 17.71 & 26.97 & 25.33 & 15.36 \\
$H$ & 1.27 & 1.26 & 1.28 & 1.13 & 1.26 & 1.24 & 1.24 \\
\hline
\end{tabular}

* $\mathrm{Q}$ is distributed as $\chi^{2}(18)$, which gives a $5 \%$ critical value of $28.86 . \mathrm{H}$ is distributed as $\mathrm{F}(165,165)$, which gives a $5 \%$ critical value of 1.29 .

\section{Non-nested Model Selection Tests}

To demonstrate further the importance of variables other than US stock prices and the price of oil, we conduct a series of non-nested model selection tests, using conventional regression analysis that allows no role for factors other than these two. Non-nested model selection tests are used here to find out if either the Dow or the price of oil can on its own explain GCC stock prices. Consider the following two models, M1 and M2: 


$$
\begin{aligned}
& \text { M1: } p_{\mathrm{t}}=X \delta_{1}+\xi_{1} \\
& \text { M2: } p_{\mathrm{t}}=Y \delta_{2}+\xi_{2}
\end{aligned}
$$

where $X$ is an observation matrix on US stock prices, $Y$ is an observation matrix on the price of oil, $\delta_{1}$ and $\delta_{2}$ are unknown regression coefficient vectors, and $\xi_{1}$ and $\xi_{2}$ are disturbance vectors. M1 and M2 are specified as:

$$
\begin{aligned}
& \text { M1: } p_{i, t}=\gamma_{0}+\gamma_{1} \sum_{k=1}^{\infty} \theta^{k} p_{U S, t-k}+\varepsilon_{i, t} \\
& \text { M2: } p_{i, t}=\alpha_{0}+\alpha_{1} \sum_{k=1}^{\infty} \theta^{k} z_{t-k}+\varepsilon_{i, t}
\end{aligned}
$$

in which GCC stock prices are explained by a geometrically declining distributed lag of US stock prices (M1) and the price of oil (M2). The two models are said to be non-nested if the regressors of one model cannot be expressed as an exact linear combination of the regressors of the other. Obviously, M1 and M2 as represented by equations (10) and (11) are non-nested because the explanatory variables are different.

\section{Table 7}

Non-Nested Model Selection Test Results*

\begin{tabular}{cccccccc}
\hline & $\begin{array}{c}\text { Abu } \\
\text { Dhabi }\end{array}$ & Bahrain & Qatar & Dubai & Kuwait & Oman & $\begin{array}{c}\text { Saudi } \\
\text { Arabia }\end{array}$ \\
\hline $\begin{array}{ccccccc}\text { M1 vs M2 } \\
N\end{array}$ & -117.2 & -182.2 & -687.2 & -65.0 & -216.2 & -3941.7 & -75.2 \\
$N T$ & -112.6 & -173.8 & -509.8 & -63.8 & -200.8 & -703.2 & -71.5 \\
$E N$ & 1054.8 & 1723.0 & 3852.7 & 598.6 & 1751.2 & 4000.1 & 366.6 \\
& & & & & & & \\
M2 vs M1 & & & & & & & \\
$N$ & -19.1 & -16.3 & 4.0 & -44.2 & -29.2 & 4.75 & -41.9 \\
$N T$ & -18.4 & -16.1 & 4.0 & -43.6 & -28.9 & 4.78 & 40.6 \\
$E N$ & 180.8 & 126.5 & 24.5 & 403.7 & 259.3 & 70.95 & 215.2 \\
\hline
\end{tabular}

*N and NT have t distribution, whereas EN has F distribution.

Three model selection tests were used: $\mathrm{N}$ is the Cox test derived in Pesaran (1974), $N T$ is the adjusted Cox test derived in Godfrey and Pesaran (1983), and $E N$ is the encompassing test proposed, inter alia, by Mizon and Richard (1986). The $N$ and $N T$ test statistics have $\mathrm{t}$ distribution, whereas the encompassing test has $\mathrm{F}$ distribution. The tests were run both ways for M1 versus M2 and M2 
versus M1. When M1 was tested versus M2, the null hypothesis was that M1 is a better model (in terms of specification) than M2. A significant test statistic indicates that M1 is not a better model than M2. When M2 was tested against M1, the null is that M2 is a better model than M1. A significant test statistic indicates that M2 was not a better model than M1. If we obtain significant test statistics both ways, this means that the two models are misspecified (that is, neither US stock prices nor the price of oil can explain GCC stock prices on their own). The econometrics of non-nested model selection tests can be found in Pesaran and Pesaran (1997).

The results of the non-nested model selection tests are reported in Table 7. ${ }^{7}$ As we can see, the tests statistics are significant both ways in all seven cases. The implication of these results is that a model in which GCC stock prices are determined by U.S. stock prices alone or the price of oil alone, without allowing

a role for other factors, are misspecified. Notwithstanding the superiority of the price of oil as an explanatory variable over US stock prices, other factors played perhaps a more important role in shaping GCC stock prices during the period under examination.

\section{Discussion of the Results and Concluding Remarks}

The price of oil goes some way in explaining disparities in the behaviour of GCC stock markets, but it cannot explain the full picture. For example, it can be argued that the stock market of Abu Dhabi rose more than the stock market of Dubai when oil prices were rising because Abu Dhabi is more dependent on oil than Dubai. Likewise, the stock market of Bahrain recorded the lowest rise when oil prices were rising and the lowest decline when oil prices were declining because Bahrain is very low on oil. However, the price of oil cannot explain why the stock market of Oman rose by over 100\% in 2007.

Other possible factors that may explain the empirical results, particularly the significance of the components, include the behaviour of foreign investors, exposure to the domestic real estate market, leverage and the liquidity position. Since no precise figures are available on foreign participation in GCC stock markets, it is not possible to say anything definitive. However, one proposition that makes some sense is that the GCC stock markets kept on rising after the collapse of the Dow because investors who liquidated their positions in the U.S. (and other developed markets) moved to emerging markets, including the GCC markets, thus sustaining the bubbles there. But when foreign investors started to pull out, because they were in need of dollar liquidity, GCC markets collapsed.

It is more plausible, however, to explain the behaviour of the GCC stock markets in terms of domestic factors, including exposure to overheated real estate markets, unsustainable levels of leverage and shallow liquidity positions.

\footnotetext{
${ }^{7}$ Equations (10) and (11) were estimated on the assumption that $\theta=0.6$. The higher the value of $\theta$ (ranging between zero and one), the greater the weight given to more recent observations of the underlying explanatory variable.
} 
These factors may explain why the stock market of Dubai declined much more than any of the other six markets. Dubai has been experiencing unsustainable growth in the real estate sector financed by foreign borrowing. When foreign financing became difficult and liquidity started to dry up, the real estate market was badly hit and listed companies started to incur huge losses, dragging the stock market down. The same chain of events took place in other markets, but to a lesser extent than in Dubai.

But irrespective of what the most valid explanation is, the empirical results of this study clearly show that contagion was not the reason (at least not a major reason) for the bubble and crash behaviour exhibited by the GCC markets. The main objective of this paper was stated at the outset as the desire to find out evidence for or against stock market contagion from the US to the GCC markets. The evidence undermines, if not rejects, the contagion hypothesis.

Author information: Imad Moosa is a Professor in the Department of Accounting and Finance, Faculty of Business and Economics, Monash University, Melbourne.Phone: +61399031472. E-mail: imad.moosa@buseco. monash.edu.au

\section{References}

Business Monitor International (2008). Credit crunch gets local: Key implications, 18, 6-7.

Godfrey, L.G., and Pesaran, M.H., (1983). Tests of non-nested regression models: Small sample adjustments and Monte Carlo evidence. Journal of Econometrics, 21, 133-154.

Harvey, A.C., (1989). Forecasting: Structural time series models and the Kalman filter. Cambridge: Cambridge University Press.

Harvey, A.C., (1997). Trends, cycles and autoregressions. Economic Journal, 107, 192-201.

Hussain, S., (2008, November). Challenges in GCC banks: Impact of the financial Ccrisis. Paper presented at the SMEs Conference, Bahrain. Retrieved from http://www.oecd.org/dataoecd/45/27/41728432.pdf.

Koopman, S.J, Harvey, A.C., Doornik, J.A. and Shephard, N., (1995). Stamp 5.0: Structural time series analyser, modeller and predictor. London: Chapman and Hall.

Ljung, G.M., and Box, G.E.P., (1978) On a measure of lack of fit in time series models. Biometrika, 65, 297-303.

Mizon, G.E., and Richard, J.F., (1986). The encompassing principle and its application to non-nested hypotheses. Econometrica, 54, 657-678.

Moosa, I.A. (2006) Structural time series modelling: Applications in economics and finance. Hyderabad: ICFAI University Press. 
Moosa, I.A., and Gazos, T., (2009). The monetary view of exchange rate determination under hyperinflation. Hyderabad: ICFAI University Press.

Pesaran, M.H. (1974). On the general problem of model selection. Review of Economic Studies, 41, 153-171.

Pesaran, M.H., and Pesaran, B. (1997). Working with Microfit 4.0: Interactive econometric analysis. Oxford: Oxford University Press.

Woertz, E., (2008, October) Impact of the US financial crisis on GCC countries. GRC Report. 